\title{
Further evidence of the efficacy of co-trimoxazole in granuloma venereum*
}

\author{
SARDARI LAL AND B R GARG \\ From the Department of Dermatology and Sexually Transmitted Diseases, Jawaharlal Institute of \\ Postgraduate Medical Education and Research, Pondicherry, India
}

SUMMARY One hundred and sixteen patients with granuloma venereum were treated with cotrimoxazole two tablets twice daily. All the patients responded; most of them required treatment for 10-15 days. Only two patients had recurrences, which were probably due to reinfections. No side effects of the drug occurred. Co-trimoxazole is considered to be the treatment of choice for granuloma venereum because of its high efficacy, few side effects, easy administration, and absence of any risk of masking concomitant syphilis.

\section{Introduction}

The efficacy of co-trimoxazole in the treatment of granuloma venereum was studied in 10 cases by Garg et al. ${ }^{1}$ In the present paper the results of treatment of a further 116 patients are presented.

\section{Patients and methods}

One hundred and sixteen patients (84 male and 32 female) attending the Department of Dermatology and Sexually Transmitted Diseases, Jipmer Hospital, Pondicherry, between February 1978 and August 1979 , were diagnosed as having granuloma venereum by the demonstration of Donovan bodies and included in the study.

The duration of the disease was less than 30 days in 37 patients, between 31 days and one year in 71, and more than a year in eight.

\section{TREATMENT}

All the patients were given two tablets of cotrimoxazole twice daily by mouth (each tablet containing trimethoprim $80 \mathrm{mg}$ and sulphamethoxazole $400 \mathrm{mg}$ ). Lesions were noted and smears for Donovan bodies repeated on the third, fifth, and seventh days of treatment. Patients were observed for any side effects.

\footnotetext{
* Paper read at the Fourth National Conference of the Indian Association for the Study of Sexually Transmitted Diseases, Visakhapatham, 23-24 February 1980

Address for reprints: Dr S Lal, Department of Dermatology and STD, Jawaharlal Institute of Postgraduate Medical Education and Research, Pondicherry, India

Received for publication 13 March 1980
}

\section{FOLLOW-UP}

When the lesions were healed the patients were discharged and asked to come back for examination once a month. Patients who did not reattend were recalled by post at least twice.

\section{Results}

Donovan bodies disappeared from tissue smears after treatment for five days and the lesions healed after treatment for 7-22 days in all cases. The mean duration of treatment required was about $12 \cdot 5$ days; 16 patients required treatment for 7-9 days, 92 for 10-15 days, and eight for more than 15 days.

One patient developed jaundice after 11 days' treatment. Liver function tests showed total serum bilirubin $3 \cdot 2 \mathrm{mg} / 100 \mathrm{ml}(54 \cdot 7 \mu \mathrm{mol} / \mathrm{l})$, direct serum bilirubin $2 \cdot 2 \mathrm{mg} / 100 \mathrm{ml}(37 \cdot 6 \mu \mathrm{mol} / \mathrm{l})$, SGOT 68 units, SGPT 78 units, and serum alkaline phosphatase 22 units. Co-trimoxazole was stopped and the patient recovered from his hepatitis; the genital lesions healed without further treatment. This complication was most likely due to a coincidental viral hepatitis. Apart from this incident no other side effects were seen in the other patients.

Forty-five patients attended for follow-up examination; of these $\mathbf{4 3}$ did not show any evidence of recurrence. One patient, whose lesions recurred two months after treatment, may have been reinfected by his wife, who had not been treated. The remaining patient defaulted and the cause of recurrence could not be determined.

\section{Discussion}

All the 116 patients responded to treatment with cotrimoxazole; the majority (92) required treatment for 
10-15 days. Only two of these patients had a recurrence of the disease about two months after treatment. Thus the drug is highly effective for the treatment of granuloma venereum.

Co-trimoxazole appears to be as effective as, if not more so than, streptomycin or tetracycline. It shares with streptomycin the advantage of not masking a concomitant early syphilitic infection. ${ }^{2}$ Side effects of co-trimoxazole were negligible compared with those of streptomycin, which produces giddiness in about $16 \%$ of patients with the dosage used for this disease. ${ }^{3}$ Another advantage is that it is also effective against gonorrhoea ${ }^{4}$ and lymphogranuloma venereum, ${ }^{5}$ whereas streptomycin is not effective against either of these diseases. Lastly, ease of administration of the drug is another advantage over streptomycin, for which twice daily injections are required.

Co-trimoxazole can thus be considered to be the drug of choice for the treatment of granuloma venereum in a dose of two tablets twice daily for 10-15 days. Its higher cost compared with that of streptomycin hinders its recommendation as the routine treatment for the disease.

We are grateful to the Director of our Institute for permission to report these findings. Our thanks are also due to the residents, laboratory technician, and social worker of the department for their help in the study.

\section{References}

1. Garg BR, Lal S, Sivamani S. Efficacy of co-trimoxazole in Donovanosis. Br J Vener Dis 1978; 54:348-9.

2. Svindland HB. Treatment of gonorrhoea with sulphamethoxazole-trimethoprim. Lack of effect on concomitant syphilis. Br J Vener Dis 1973;49:50-3.

3. Lal S. Continued efficacy of streptomycin in the treatment of granuloma inguinale. $\mathrm{Br} J$ Vener Dis 1971;47:454-5.

4. Sowmini CN, Vijayalakshmi K, Rao GC, Gopalan KN, Kumaraswamy E. Septrin in the treatment of gonorrhoea. Indian J Dermatol Venereol Lepr 1976;42:110-2.

5. Chandrasekaran NK. Efficacy of trimethoprim-sulphamethoxazole combination in the treatment of lymphogranuloma venereum. Bulletin of the South-east Asian Western Pacific Region Branch of the International Union against Venereal Diseases and the Treponematoses 1976;1:21-2. 